Anderson Reis de Sousa'

(ㄱ) https://orcid.org/0000-0001-8534-1960

Wanderson Carneiro Moreira²

Ohttps://orid.org/0000-0003-2474-1949

Aline Macêdo Queiroz

Ohttps://orcid. org/0000-0002-7374-011X

Murilo Fernandes Rezende 4

Ohttps://orcid org/0000-0002-6262-9299

Jules Ramon Brito Teixeira

Ohttps://orcid.org/0000-0002-8443-7810

Magno Conceição das Merces ${ }^{6}$ Dhtps://orcid org/0000-0003-3493-8606

Adailson Vieira da Silva

OChttps://orcid.org/0000-0001-9766-082X

Emerson Lucas Silva Camargo ${ }^{8}$ Ohttps://orcid.org/0000-0002-6119-5193

\section{COVID-19 pandemic decrease men's mental health: background and consequence analysis}

\author{
A pandemia da COVID-19 piora a saúde mental de \\ homens: análise de antecedentes e consequentes
}

DOI: 10.1590/0047-2085000000327

\begin{abstract}
Objective: To analyze, from the perspective of self-report of antecedents and consequences, how the COVID-19 pandemic decrease the health of men living in Brazil. Methods: Qualitative study, conducted with 200 men living in all regions of Brazil through the application of a semi-structured instrument, hosted on an online platform. The data were analyzed with the Collective Subject Discourse method and anchored in the theoretical framework of Dialectical Historical Materialism. Results: The COVID-19 pandemic decrease men's mental health because it worsened the history of personal, affective, family, occupational, dysfunctional and/or morbid problems, causing consequences of psychic somatization, family dissolution, end of affective relationship, marital conflicts, social isolation, financial difficulty, vulnerability of the work situation and occupational exhaustion, sudden changes in behavior, barriers in access to health care and impaired experiences of death and grief. Conclusion: Social support networks need to be strengthened in order to minimize the direct and indirect impacts caused by the pandemic materiality for mental health and the various dimensions of life affected.
\end{abstract}

KEYWORDS

Pandemics, COVID-19, coronavirus infections, mental health, men's health.

\section{RESUMO}

Objetivo: Analisar, sob o prisma do autorrelato de antecedentes e consequentes, como a pandemia da COVID-19 piora a saúde de homens residentes no Brasil. Métodos: Estudo qualitativo, realizado com 200 homens residentes em todas as regiões do Brasil, mediante a aplicação de instrumento semiestruturado, hospedado em plataforma on-line. Os dados foram analisados com o método do Discurso do Sujeito Coletivo e ancorados no referencial teórico do Materialismo Histórico Dialético. Resultados: A pandemia da COVID-19 piorou a saúde mental dos homens, porque aprimorou a história problemática pessoal, afetiva, familiar, ocupacional, disfuncional e/ou mórbida, e causa consequências de somatização psíquica, dissolução familiar, fim do relacionamento afetivo, conflitos conjugais, isolamento social, dificuldade financeira, vulnerabilidade da situação de trabalho e desgaste ocupacional, mudanças repentinas de comportamento, barreiras no acesso aos cuidados de saúde e experiências de morte e luto prejudicadas. Conclusão: É necessário fortalecer redes de apoio social, a fim de minimizar os impactos diretos e indiretos causados pela materialidade da pandemia para a saúde mental e as várias dimensões da vida afetadas.

\section{PALAVRAS-CHAVE}

Pandemias, COVID-19, infecções por coronavírus, saúde mental, saúde de homens.
Received in: Aug/13/2020. Approved in: Mar/28/2021

1 Federal University of Bahia, School of Nursing, Salvador, BA, Brazil.

2 University of São Paulo, School of Nursing, São Paulo, SP, Brazil.

3 Federal University of Pará, Belém, PA, Brazil.

4 Brazilian Psychiatric Association, Aracaju, SE, Brazil.

5 State University of Feira de Santana, Feira de Santana, BA, Brazil.

6 State University of Bahia, Salvador, BA, Brazil.

7 University of Fortaleza, Fortaleza, CE, Brazil.

8 University of Ribeirão Preto, Ribeirão Preto, SP, Brazil.

Address for correspondence: Anderson Reis de Sousa. Universidade Federal da Bahia, Escola de Enfermagem. Rua Basílio da Gama, 241, Canela - 40231-300 Salvador, BA, Brasil. E-mail: anderson.sousa@ufba.br 


\section{INTRODUCTION}

SARS-CoV-2 (Severe Acute Respiratory Syndrome Coronavirus 2), which causes the disease known as COVID-19, which emerged in China, is the largest global health problem of this generation'. The World Health Organization (WHO) recognized COVID-19 as a pandemic, in which diverse actions had to be taken by agencies and governments at the global level'2.

Men and women are equally prone to SARS-CoV-2 infection; however, a pattern of predominance of mortality for males has been identified in several countries, and repeated in Brazil, although the reasons for this occurrence are not yet fully explained ${ }^{3}$. Added to this context, there is a significant gap in scientific production directed to male health that presents an analysis that goes beyond the dimension of morbidity and mortality and involves the knowledge, attitudes, behaviors and practices adopted by men in the health-disease context, as occurs in pandemic moments ${ }^{4,5}$. Thus, it also reinforces the fact that the relational aspects of gender and masculinities and men's mental health reserve sterotypes and stigmas to be overcome, which confers greater support and justification for the development of this study.

The absence of cure, effective treatment and mitigation measures against COVID-19 (distancing and social isolation) have caused fear in the population to contract the disease, which affects the feeling of social, labor and even family/ affective insecurity, uncertainty of the daily functioning of society and changes in interpersonal relationships ${ }^{6-8}$. Nevertheless, particularly regarding the male mental health situation, the findings reveal negative feelings and emotions, increased stress levels and the emergence of somatization, leading the male public to psychic suffering and depressive behavior, deserving greater attention, especially because of the difficulty of the majority of the male public in dealing with and regulating emotions and feelings, self-managing mental health care and employing effective strategies to cope with mental health problems 9 .

In this context, understanding the factors that influence and affect men's mental health in the current pandemic scenario, in terms of background and consequence elements, is necessary, since evaluating a crisis as chained and progressive moments can contribute to understanding specificities of stressing factors related to the problemsituation and the care that should be provided. Thus, the following research question was elaborated: What are the background and consequence elements of the degradation of mental health of men living in Brazil experiencing the COVID-19 pandemic? To answer this question, this study aims to analyze, from the perspective of self-reported antecedents and consequences, how the COVID-19 pandemic decrease the health of men living in Brazil.

\section{METHODS}

\section{Type of study}

Qualitative study, structured under the epistemological basis of Dialectical-Historical Materialism (DHM) ${ }^{10,11}$.

\section{Study site, participants and data collection}

The research was carried out in a virtual environment with cisgender, transgender and non-binary men living in Brazil. The research was conducted during the quarantine and social distancing period, following the measures recommended by government and health authorities due to the SARS-CoV-2 pandemic.

The theoretical sample was composed of speeches of 200 men. The speeches were apprehended from the frequency of similar appearance of central meanings and ideas and subsequent internal validation of the unveiled findings ${ }^{12}$. To identify the theoretical saturation, as new speeches entered the database, two researchers independently performed a continuous process of data analysis through compilation and grouping of the identified themes. This double analysis allowed the identification of similar themes, and the theoretical saturation reached 200 speeches, represented by the absence of new elements in the treated material. A third researcher reviewed the material and ensured the theoretical saturation and reliability of the results.

Data collection was performed by applying a semistructured form hosted on a digital platform provided by Google Forms ${ }^{\circledast}$. The form consisted of closed questions related to the sociodemographic profile and open: Regarding your mental health, describe what the pandemic has been representing for you? How have you been feeling? What emotions represent your experience during it? Has the pandemic brought any change in your behavior? Have you ever noticed yourself suffering during the pandemic? Talk about it.

The participants were invited by social networks (Facebook $^{\oplus}$, Instagram ${ }^{\oplus}$ and WhatsApp ${ }^{\oplus}$ ), following a method consolidated by other studies in the literature with this public ${ }^{4,59}$. For this, the snowball technique was applied as an exploratory apprehension strategy of theoretical chain sampling ${ }^{13}$. Safety criteria was guaranteed to maintain confidentiality, protection and adequate storage of data.

\section{Data analysis}

The data were processed in the NVIVO12 software, which makes it possible to organize, systematize and process qualitative data, allowing to locate convergences, divergences, complementarities, co-color and the appearance frequency of data and coding ${ }^{14}$. For the methodological analysis, the Collective Subject Discourse $(\mathrm{CSD})^{15}$ was used, which allowed grasping Central Ideas of the phenomenon of collective representation investigated.

The methodological framework allowed us to apprehend discursive fragments on the form of Key Expressions, which 
reveal the essence of the content of social representations presented in the data, such as the underlying theory used in the interpretation of the same, and allowed to form collective statements. These collective statements mark the presence of a person's collective thought of a single collective subject in the discourse ${ }^{15}$. Finally, these Key Expressions reveal the Central Ideas, which, as synthetic formulas, name the meanings of each statement and expression the grouping of discourses in the form of analytical categories ${ }^{15}$.

The interpretation of the findings is anchored in the conceptual bases of $\mathrm{DHM}^{10,11}$. From a Marxist current, DHM constitutes a political, sociological and economic theory that provides, from its analytical dimensions, observing social phenomena of conjuncture character, such as social changes, the exploitation of manpower, work, social class, contradictory social movements, which in turn produce disaggregation and impacts on human mental health ${ }^{10,11}$.

\section{Ethical procedures}

The research project was approved by the Research Ethics Committee under the opinion number: 4.087.611, linked to a larger project, and the consent for participation was obtained online. Anonymity and confidentiality of the data generated by the study participants were guaranteed.

For the identification of participants, who according to the Collective Subject Discourse method are presented in the entire group investigated, is represented by the description: CSD of men living in Brazil during the COVID-19 pandemic.

\section{RESULTS}

The participants were men between 18 and 67 years old, mostly living in the Northeast region of the country (72.3\%), cisgender (93.6\%), homosexual (47.7\%), self-reported brown race/color (39.3\%), with complete higher education (66.7\%). The majority reported living at home (67.45\%), living with non-elderly relatives (21.95\%) and have an approximate income above five minimum wages (33.2\%). Of these, 18 self-reported having tested positive for SARS-CoV-2.

The collective discourse of men revealed background and consequence elements of degradation to male mental health in the COVID-19 pandemic context in Brazil. These discourses are illustrated in Central Ideas anchored in two major theoretical categories of analysis, namely.

\section{SYNTHESIS-DISCOURSE 1: BACKGROUND ELEMENTS THAT TRIGGER AND INTENSIFY THE DEGRADATION OF MENTAL HEALTH}

The collective discourse of men evidenced the emergence of elements present in a set of background factors triggering and intensifying the degradation of male mental health during the course of the pandemic in Brazil.

\section{Central Idea 1A: Personal and affective background}

The uncertainty, tension and fear of what might be coming only made my mental state worse with the emergence of the pandemic in Brazil. Soon after, several adverse situations emerged, such as the fear of close people being contaminated, the longing for college, the sadness for the deaths caused by the disease, the absence of cure and specific treatment, the sadness for the difficulty in maintaining an affective relationship, seclusion, worry and the inadaptation to home office work and my difficulty in having to stay indoors for so long. I try to think calmly so as not to despair, but sometimes I am not able to act before situations that began to arise after the beginning of the pandemic and ended up generating negative impacts, because they lead me to have concerns not only with the present moment, but also with the future moment. (CSD of men living in Brazil during the COVID-19 pandemic)

\section{Central Idea 1B: Family background}

In addition to other situations, the family fact has affected my mental health, mainly because of my father who is a smoker, a grandmother who is elderly and other family members who belong to the risk groups. This situation started to put me on alert all the time. Having to break up with my family has also made me uncomfortable, longing and sad. I also have a baby and the monitoring of his growth has been intense, requiring many assignments and this also generates concern, tensions and wear, after all, it is a huge change and a total change in daily routines. (CSD of men living in Brazil during the COVID-19 pandemic)

\section{Central Idea 1C: Occupational background}

The fact of a professional who works in a service and has to work on the front line, with direct contact with people who may be affected with COVID-19, makes my mental health shaken. I try to seek encouragement to continue exercising my work and for this I seek to strengthen contact with my family and other people who are not from my work, but it has not been an easy situation, because distressed and sad most of the time. (CSD of men living in Brazil during the COVID-19 pandemic)

\section{Central Idea 1D: Social background}

My mental health began to be affected in the very beginning of the pandemic, when I started to see reports of sick and dead people in several countries, because the numbers are frightening. After that, I started reading, watching videos and reports about the disease, which already began to generate fear and dread and I also realized that the dissemination of incorrect and large volume information that came to me only jeopardized my mental state. This situation of chaos in the city, 
added to the seclusion generated by the distancing of people only increases anxiety. I feel that one of the main aggravating factors has been social isolation and uncertainty, because the disruption of contact with people, especially friends, has made me feel very lonely. (CSD of men living in Brazil during the COVID-19 pandemic)

\section{Central Idea 1E: Dysfunctional and/or morbid background}

Before the pandemic, I already lived with anxiety, sleep and mood disorders, and under a drug treatment to treat bipolarity and now, with the onset of the pandemic, the symptoms are worse. I have been very anxious. And the problems are not restricted only to my mental health, because I also have to deal with other comorbidities, with Diabetes and Hypertension, and with the possibility of contamination of COVID-19, because even following the recommendations of prevention, washing hands, wearing masks, I live the constant unpleasant feeling of vulnerability. Any sneezing or coughing already freaks me out and this gets worse when I need to leave the house and get in touch with other people, such as on a bus or subway. All this I have been through further raises the pressure on my mental state due to the permanent state of tension. (CSD of men living in Brazil during the COVID-19 pandemic)

\section{SYNTHESIS-DISCOURSE 2: CONSEQUENCE ELEMENTS THAT CAUSE DEGRADATION OF MENTAL HEALTH}

Upon experiencing the pandemic and the prolongation of social isolation, the male discourse revealed the existence of elements that cause degradation of mental health within the specificities present in the Brazilian territory. These consequence elements are illustrated in the Central Ideas below.

\section{Central Idea 2A: Psychic somatization and mental health problems}

The pandemic has affected my psychological, causing many concerns, which makes me realize that my mental health is shaken. I have felt its oscillation, with moments of restlessness and agitation. My breath has been short, and sometimes I feel like being away from my own body, at other times, I feel exhausted. I had anxiety and panic attacks and started having episodes of insomnia. My thoughts are fast paced and this has impaired my sleep during the night. (CSD of men living in Brazil during the COVID-19 pandemic)

\section{Central Idea 2B: Family dissolution}

My family life was totally impacted. I cannot be closer to my father and mother to care for them and closely check on how they are. (CSD of men living in Brazil during the COVID-19 pandemic)

\section{Central Idea 2C: End of affective relationship}

Intensified by social isolation, my affective relationship reached the end. I noticed that right after completing a week of quarantine I had already had problems with my partner. The dialogue began to wear out and we ended the relationship. This situation has still been difficult to overcome. (CSD of men living in Brazil during the COVID-19 pandemic)

\section{Central Idea 2D: Marital conflicts}

After the pandemic, my partner and I have been in conflict many times. In a single day, we have argued for several reasons, generating exaltation of unpleasant moods and feelings towards one another. These conflicts also alter my mental state, which is the result of stress and makes me displeased for having fought. (CSD of men living in Brazil during the COVID-19 pandemic)

\section{Central Idea 2E: Social isolation}

The conversations I had before with friends were impaired. I am distant from the family, I have difficulty going to a medical service because of the pandemic and the need to comply with quarantine, I can no longer perform physical exercises outside the home and had to interrupt my studies at the university. This atmosphere of empty city, the people inside their homes is very strange and causes me fear of a worse situation. (CSD of men living in Brazil during the COVID-19 pandemic)

\section{Central Idea 2F: Financial difficulty, employment vulnerability and occupational wear}

With the pandemic, new routines were generated, a lot of work and a lot of tiredness. Besides, I am tense and worried about the possibility of being unemployed. I already have family members who are experiencing unemployment and it affects my mental health a lot. Keep working even during the pandemic daily exposes me to risk because of the vulnerability of my employment relationship and economic situation. My financial situation is getting more unstable and difficult every day. I work in a very exposed function and I am afraid to keep working and be contaminated. Even with all this exposure, I have no other way out, I need to go not to face greater financial difficulties to keep my living. (CSD of men living in Brazil during the COVID-19 pandemic)

\section{Central Idea 2G: Sudden behavioral changes}

As I stay athome most of the time, I have accessed social networks more frequently and I have noticed that this consumption is constant and is making me sick. I still cannot manage my time very well and not having the situation under control makes me 
feel bad. With reduced mobility, I have suffered from anxiety, which is worse. (CSD of men living in Brazil during the COVID-19 pandemic)

\section{Central Idea 2H: Barriers in the access to health care and treatment}

Since the beginning of the pandemic, I have faced difficulties in carrying out the clinical follow-ups that I need to do due to the presence of a chronic disease. The treatment, consultations and evaluations have all been suspended and all this makes me apprehensive and worried because I am afraid of having complications. In addition, I have faced difficulty in requesting the home care service, because I have an elderly relative who needed care, but we were not met and we were also informed that hospital admissions were restricted. With this entire situation, I get more anxious and afraid of needing to use some health service during the pandemic, because in addition to the risk of contamination by Coronavirus I will have difficulty receiving aid. (CSD of men living in Brazil during the COVID-19 pandemic)

\section{Central Idea 2l: Death, terminality and mourning experience}

It has been a very critical and difficult situation. I lost a close relative, he needed help, but he did not have the necessary support, because everything happened during the early hours, and the people closest to him were quarantined and could not help, so he passed away. The whole family and I are very shaken by this loss. I know I need to help comfort my loved ones, but I confess that my emotional is also shaken. We could not even say goodbye. Besides, all the time we watch scenes of large-scale deaths, which makes me even more depressed. (CSD of men living in Brazil during the COVID-19 pandemic)

\section{DISCUSSION}

The results revealed that men find it difficult to access health services, although this fact is not exclusive to the current pandemic scenario experienced ${ }^{16}$. There was an intensification of this difficulty of access, especially to mental health services. Some individuals use online care, which are not available to the entire population, requiring government attention regarding the provision of psychosocial care services in the country, such as the implementation of impact actions during and after the pandemic period $\mathrm{d}^{4,5,8}$.

Men who have lost relatives or friends may develop pathological mourning, a type of adjustment disorder that includes symptoms such as distress and emotional disturbance, by having the affective and loving structure compromised and abruptly impaired with social isolation ${ }^{17}$. In this particular case, there is need to consider the social construction of masculinities as an influencing component in the regulation of emotions triggered by men, as well as coping strategies employed by them from the experience of stressing agents, as occurs with the pandemic ${ }^{6}$. A study conducted with men in Brazil during the COVID-19 pandemic revealed the emergence of negative emotions, such as anxiety, apprehension, insecurity, restlessness, instability and fear'.

Conjuncture situations of socioeconomic nature, such as unemployment and poor financial situation, are risk factors for the mental illness of men, especially those who are wage earners of families, a situation also observed in other countries, especially those in development ${ }^{18,19}$. Once emotionally ill, such precipitating factors become factors that maintain mental illness, as they are complicating the resolution of the mental disorder already installed, in which poverty drives male depression.

To transform production in this time of pandemic and meet the needs, society develops instruments and devices with which the production of the social life becomes complex. This human ontological trait, under the regime of private property proper to capitalism, can no longer be executed in this modality, because not only the instruments but also the elements of nature itself (land, water, biomes) have been passing to the private domain ${ }^{20}$. In this situation, men are put at risk of illness and this is the central contradiction of capitalism, which produces its devastating effects on human life.

In view of these conjuncture aspects, the discourse of men reveals the presence of typologies of the precariousness of work, with the weakening of organizations, the mischaracterization of the symbolic place of work, health insecurity at work, loss of identity at work in not only the individual perspective, but also collectively. The findings also show the elimination of the worker's right materialized in the loss of benefits, delays and wage reductions, employment instabilities and vulnerabilities in the work process, such as in the group of men who work in the services considered essential.

Intersectionality should be considered when analyzing work relationships and mental illness in the context of the pandemic, after all, black race/color (which includes blacks and pardos) is directly associated with unemployment and poverty in Brazil ${ }^{21}$. Thus, black men are at higher risk of mental illness because they are black. Furthermore, structural racism greatly increases this risk, because, compared to white men, black men are those who develop more precarious activities and are the first to be dismissed in a situation of staff reduction.

Unemployment increases the feeling of uncertainty and lack of future prospects, deteriorating psychological wellbeing before the inability to enter the labor market and all 
that this may mean, 22 a situation that is already part of the daily life of black Brazilians. It implies highlighting that the precariousness of work was already a reality in force in Brazil, however, with the advent of the pandemic, the precarious phenomena are accentuated and sharpened, which makes the male mental health situation even more vulnerable. Paying attention to these consequences is essential for reducing absenteeism, reducing productive capacity and the workforce and maintaining well-being and quality of life at work. $^{8}$

Mental disorders, such as depression, decrease man's ability to work and may even imply partial or definitive absence from work, resulting in increased poverty and rehabilitation costs for the Unified Health System and Social Security. Poverty, in turn, can hinder or prevent the individual from performing comprehensive treatment ${ }^{4,5,8}$.

Another factor present in men's discourse is the compulsive use of digital technologies. Social isolation, the fact of staying most of the time at home and the impossibility of performing activities of daily living outside the home have resulted in the use of time for virtual games and use of digital social networks. This problem was already possible among men before the pandemic, intensifying in this period ${ }^{17}$. Moreover, excessive consumption of information related to the pandemic can lead to greater damage to male mental health, causing hypervigilance, tension and apprehension.

Unmarried men, who live alone, have a higher risk of mental illness and even committing suicide. This has been associated with romantic loneliness, lack of affective support from a partner, or lack of family support, whether emotional or financial. In order to increase mental health enhancements, some men end up adopting or increasing the risk consumption of alcoholic beverages, tobacco, medications and other licit and/or illicit drugs to "medicate" their symptoms of anxiety and depression ${ }^{18}$. Substance abuse is an important significant risk factor for worsening mental illness ${ }^{19}$. This problem of substance abuse and its impacts on mental health can be triggered by the overlapping of consequences caused by the pandemic and anticipated by previous factors, a relationship that requires greater attention from the care-producing agents and coping-policy makers.

In many men, social isolation generates the feeling of loneliness and prevalent thoughts of the type "no one helps me", "I have no one" or "no one cares about me". These affective and cognitive alterations can precipitate mental illness, a situation endorsed by men's discourses related to family disaggregation, the end of affective relationships, marital conflicts and the very consequence of isolation ${ }^{18,19}$. The fear associated with the condition of vulnerability to Coronavirus is highlighted, considering the group of men who have comorbidities and the fear of transmitting to family members, which causes damage to their psychosocial well-being. Regarding these aspects, fear has emerged as a preponderant factor for the degradation of mental health during the pandemic, with close relationship with COVID-19 infection and feelings of uncertainty and lack of future life prospects $^{19}$.

In their routine, men build their material and subjective existence, that is, to become a man in a social reality. In the pandemic, in addition to these background and consequence dimensions, men experienced abrupt changes that directly degrade individuality, singularity, subjectivity, as well as male behaviors, attitudes and practices. These results imply the need to implement coping strategies. A study published in Brazil draws attention to the execution of individual strategies aimed at the care of special groups, as well as government ones focused on reducing the impacts caused by the COVID-19 pandemic on mental health5.

As evidenced in the discourses, some men with mental disorder already diagnosed are presenting symptomatological reagudization. For example, men with bipolar disorder with depressive episode (relapse). This finding is envisioned in the discourse that demarcates the presence of background, becoming complicating after prolonging the course of COVID-19 and its associated impacting phenomena.

Hopelessness is a debilitating feeling and can be considered a risk factor for depression and suicide. This phenomenon may be related to the dissemination of news about COVID-198. For example, television news tends to focus on and address the number of patients and deaths, to the detriment of the spread of the number of survivors and the dissemination of other good news that would bring relief and hope, further leading to changes in the sleep/wake cycle that implies poor sleep quality and eating disorders ${ }^{8}$. Research conducted in China with individuals showed psychological impact of moderate and severe aspect, with the appearance of depressive symptoms, stress and anxiety. In addition to these symptoms, physical conditions were also observed, namely: general malaise, dizziness and myalgia ${ }^{2}$. In Colombia, a study revealed a psychosocial impact through the advent of suicide cases, with a strong relationship with the confinement caused by mandatory quarantine and the lack of financial resources for family provision ${ }^{20}$. Similar results were also observed in Bangladesh ${ }^{22}$.

Some men may develop acute stress and adaptation disorders, also called acute stress reaction and adjustment disorders. Disorders grouped in this category arise as a direct consequence of severe acute stress or continued trauma. They include diverse symptoms, especially those of the depressive-anxious spectrum, such as distress, fear, excessive or exaggerated worries, somatic symptoms, and insomnia. With the pandemic, phenomena such as stigma and xenophobia can be even more degrading to men's mental health ${ }^{22,23}$. Adaptation disorders are associated with a higher risk of suicide attempts and consummation ${ }^{19}$. In addition to the 
disorders generated by the pandemic, studies have identified the presence of intensifications of preexisting diseases ${ }^{8}$.

Men's discourses highlight the occurrence of approximation with grief, daily and interrupted, which results in greater suffering and degrades their mental health situation in the pandemic context. Concerning terminality, death and mourning in the context of the COVID-19 pandemic, there is need to recognize that, with the interruption of mourning rituals and the high number of deaths, the prolonged installation of feelings of loss has degraded the mental health situation. Regarding this phenomenon, it is essential to intervene in the promotion of social-affective networks ${ }^{24}$ in the strengthening of support bonds and network, in which the psychosocial care network, specialized psychiatric care and other spheres present in mental health promotion devices in Brazil stand out. These strategies aim to ensure actions to promote psychosocial well-being during and after the pandemic context, anticipating the advent of secondary phenomena, such as posttraumatic stress and phobias, and the psychic protection and well-being of the male population ${ }^{8}$.

The limitations of this study refer to the fact that social networks and the snowball method were used to constitute the sample universe for data collection, which may have concentrated in a certain audience through which this information circulated, thus occurring a selection bias.

Health professionals, understanding the need to analyze the concrete reality of men in suffering during and after the pandemic, need to recognize the contradictory aspects of the reality of the relationships experienced by them in order to overcome the situation of alienation. In this sense, a care strategy is to stimulate the adoption of behaviors and strategies for promoting and recovering resilience, as well as strengthening social support networks for men, in order to minimize the direct and indirect impacts caused by the pandemic to mental health and the various dimensions of life affected.

Finally, this study provides substantial contributions to the advancement of scientific knowledge, as it expresses unpublished findings and presents how the COVID-19 pandemic degrades the mental health of Brazilian men under an analysis of antecedent and consequential elements. These findings support future studies on the production of care and on male health care in pandemic contexts.

\section{CONCLUSION}

Background elements that decreased of male mental health in the context of the COVID-19 pandemic were evidenced by personal, affective, family, occupational, dysfunctional and morbid factors. The elements resulting from mental health included psychic somatization, family dissolution, end of affective relationship, marital conflicts, social isolation, financial difficulty, vulnerability of the work situation and occupational wear, sudden behavioral changes, barriers in the access to health care and experiences of death and impaired mourning.

\section{INDIVIDUAL CONTRIBUTIONS}

Anderson Reis de Sousa - Study design, data collection, analysis and interpretation of data, discussion of results, writing and/or critical review of the content, final review and approval of the final version.

Wanderson Carneiro Moreira - Analysis and interpretation of data, discussion of results, writing and/or critical review of the content, final review and approval of the final version.

Aline Macêdo Queiroz - Analysis and interpretation of data, discussion of results, writing and/or critical review of the content, final review and approval of the final version.

Murilo Fernandes Rezende - Analysis and interpretation of data, discussion of results, writing and/or critical review of the content, final review and approval of the final version. Jules Ramon Brito Teixeira - Analysis and interpretation of data, discussion of results, writing and/or critical review of the content, final review and approval of the final version.

Magno Conceição das Merces - Analysis and interpretation of data, discussion of results, writing and/or critical review of the content, final review and approval of the final version.

Adailson Vieira da Silva - Analysis and interpretation of data, discussion of results, writing and/or critical review of the content, final review and approval of the final version.

Emerson Lucas Silva Camargo - Analysis and interpretation of data, discussion of results, writing and/or critical review of the content, final review and approval of the final version.

\section{CONFLICTS OF INTEREST}

The authors declare that they have no conflict of interest.

\section{ACKNOWLEDGMENT}

None.

\section{REFERENCES}

1. Fan W, Su Z, Bin Y, Yan-Mei C, Wen W, Zhi-Gang S, et al. A new coronavirus associated with human respiratory disease in China. Nature. 2020;579:265-9.

2. Cuiyan W, Riyu P, Xiaoyang W, Yilin T, Linkang X, Cyrus H, et al. Immediate Psychological Responses and Associated Factors during the Initial Stage of the 2019 Coronavirus Disease (COVID-19) Epidemic among the General Population in China. Int J Environ Res Public Health. 2020;6;17(5):1729. 
3. Jin JM, Bai P, He W, Wu F, Liu XF, Han DM, et al. Gender Differences in Patients With COVID-19: Focus on Severity and Mortality. Front Public Health. 2020;8:152.

4. Sousa AR, Carvalho ESS, Santana TS, Sousa AFL, Figueiredo TFG, Escobar 0JV, et al. Men's feelings and emotions in the COVID-19 framing. Ciênc Saúde Coletiva. 2020;25(9):3481-91.

5. Sousa AR, Santana TS, Moreira WC, Sousa AFL, Carvalho ESS, Craveiro I. Emotions and coping strategies of men to the COVID-19 pandemic in Brazil. Texto Contexto Enferm. 2020;29:e20200248

6. Ozili PK, Arun T. Spillover of COVID-19: impact on the global economy. SSRN. 2020. Doi: https://doi.org/10.2139/ssrn.3562570

7. Brooks SK, Webster RK, Smith LE, Woodland L, Wessely S, Greenberg N, et al. The psychological impact of quarantine and how to reduce it: a quick review of the evidence. Lancet. 2020;395(10227):912-20.

8. Moreira WC, Sousa AR, Nobrega MPSS. Mental disease in the general population and health professionals during covid-19: a scoping review. Texto Contexto Enferm. 2020;29:e20200215

9. Camargo ELS, Oliveira BIA, Siffoni IF, Sousa AR, Teixeira JRB, Mendes IAC, et al. Low Psychological Well-being in Men Who Have Sex with Men (MSM) During the Shelter-inPlace Orders to Prevent the COVID-19 Spread: Results from a Nationwide Study. Sex Res Soc Policy. 2021;1-10. Doi: 10.1007/s13178-021-00550-5

10. Amoras JAB, Sales APA, Sampaio ATL, Machado RM, Duarte SJH. Historical and Dialectical Materialism in Nursing Care: Integrative Review. Rev Enferm UFPE on line. 2016;10(4):1307-14.

11. Soares (B, Campos CMSi, Yonekura T. Marxism as a theoretical and methodological framework in collective health: implications for systematic review and synthesis of evidence. Rev Esc Enferm USP. 2013;47(6):1403-9.

12. Fontanella BJB, Magdaleno JR. Theoretical saturation in qualitative research: Psychoanalytical contributions. Psicol Estud. 2012;17(1):1763-71.
13. Biernacki, P, Walford, D. Snowball sampling: Problems and techniques of chain referral sampling. Social Methods Res. 1981;10(2):141-63.

14. Hilal AH, Alabri SS. Using NVivo for data analysis in qualitative research. Int Interdiscip J Educ. 2013;2(2):181-6.

15. Lefevre $F$, Lefevre AMC. 0 discurso do sujeito coletivo: um novo enfoque em pesquisa qualitativa. Caxias do Sul: Educs; 2003

16. Sousa AR, Queiroz AM, Florencio RMS, Portela PP, Fernandes JD, Pereira A. Homens nos serviços de atenção básica à saúde: repercussões da construção social das masculinidades. Rev Baiana Enferm. 2016;30(3):1-10.

17. Seminog 00 , Goldacre MJ. Risk of pneumonia and pneumococcal disease in people with severe mental illness: English record linkage studies. Thorax. 2013;68:171-6.

18. Yao H, Chen JH, Xu YF. Patients with mental health disorders in the COVID-19 epidemic. Lancet Psychiatry. 2020;7(4):e21.

19. Ornell F, Schuch JB, Sordi A0, Kessler FHP. "Pandemic fear" and COVID-19: mental health burden and strategies. Braz J Psychiatry. 2020;(42):3.

20. Gonzalez-Diaz JM, Cano JF, Pereira-Sanchez V. Psychosocial impact of COVID-19-related quarantine: reflections after the first case of suicide in Colombia. Cad Saúde Pública. 2020;36(6):e00117420.

21. Lima M. "Race" and poverty in metropolitan contexts. Tempo Soc. 2012;24(2):233-54.

22. Mamun MA, Griffiths MD. First COVID-19 suicide case in Bangladesh due to fear of COVID-19 and xenophobia: possible suicide prevention strategies. Asian J Psychiatr 2020;51:102073.

23. Asmundson GJG, Taylor S. Coronaphobia: Fear and the 2019nCoV outbreak. J Anxiety Disord. 2020;70:102196.

24. Crepaldi MA, Shimidt B, Noal DS, Bolze SDA, Gabarra LM. Terminality, death and grief in the COVID-23. Pandemic: emerging psychological demands and practical implications. Estud Psicol. 2020;37:e200090. 